\title{
Enjoying dentistry again
}

\section{By Simon Francis, Rothbury, UK}

$\mathrm{I}$ get up at 6.30 am and have coffee with toast and Marmite for breakfast at home

In Rothbury, where I live with my wife and daughter.

I'm an associate dentist with Genix Healthcare in Whitley Bay, a 35-mile drive away. It's a four-surgery practice, mostly NHS, with some of the dentists offering more specialised private treatments for patients who want them.

At the present time I'm doing aerosol generating procedures (AGPs) in the morning session and seeing non-AGP emergencies and check-ups in the afternoons. I have Tuesdays off and work 9-5 with a late night on a Wednesday.

At school, I knew I wanted to do something medical or science based. I tried some work experience and found that dentistry seemed to click with me.

Since qualifying from Newcastle, I've been an associate, a practice owner and back to associate again. Owning a practice led to health problems including severe anxiety and depression. I've recovered now and enjoy dentistry again.

The best part of the job is getting an anxious patient and changing their mind about dentistry and dentists. The most challenging part of it is not allowing stress to build up to intolerable levels.

The team I work with is great. We all pull together and that has been so important recently. I don't think we would have coped as well with the pandemic if we hadn't been so close. We have regular meetings and hope to do more social things next year.

I normally get home sometime after 6 .

Outside work I play the guitar, go hill walking and do some landscape and wildlife photography. At weekends I try to get outside with the family - I like to get some fresh air after being in the surgery all week.

I'm not particularly strict with my own diet and oral health, but I am with my daughter's!

I go to bed around $10.30 \mathrm{pm}$.

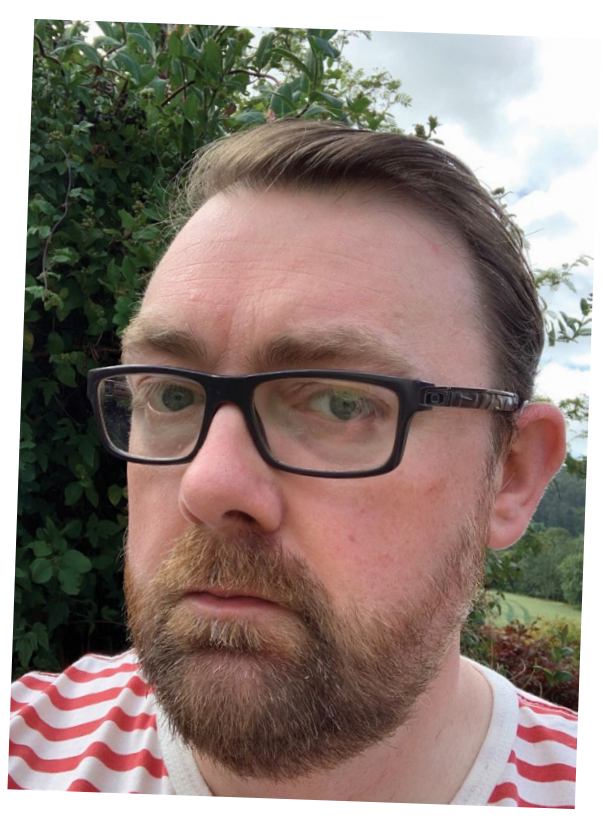

For 2021, the priority is getting back to normal. My career ambition is to provide the best care I can.

If I hadn't gone into dentistry, I would be the guitarist in a moderately successful indie guitar band.

\section{FROM THE ARCHIVE}

\section{Ferraris and holidays}

This news story was published in the BDJ on 13 January 2001, in Volume 190 page 46.

Surprisingly, a recent survey conducted by the Bank of Ireland at the London Dental Showcase revealed that what dentists desire most are a new sports car and more time off work. The bad news for those of a romantic inclination is that only a small percentage wished for 'Mr. or Mrs. Right', a similarly small percentage to those that asked for 'more money'. Unfortunately, the choice of cars rather belies the anti-materialist message with a Ferrari featuring just ahead of a Jaguar XK8 in the list of dream cars. The serious aspect to the exercise was that the Bank of Ireland donated $£ 1$ to the BDA Benevolent Fund for each wish made. The exercise raised $£ 500$ and Chris Strevens (front right) and Andy Acton (front left) of the Bank

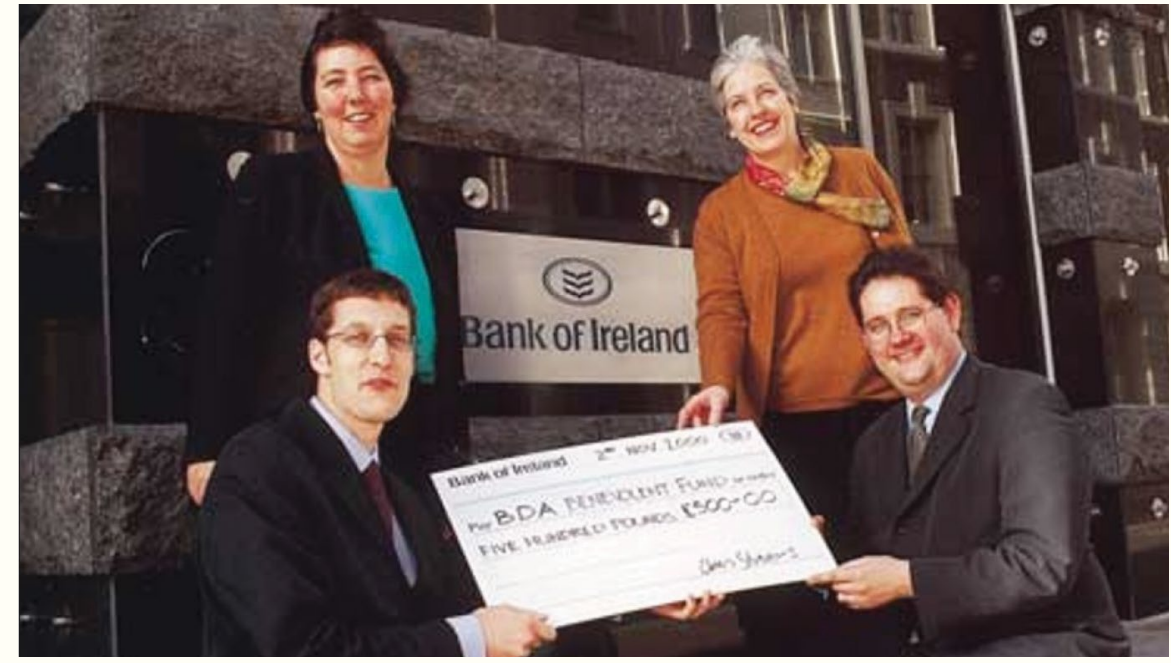

of Ireland are shown above presenting a check to Sylvia Theaker (back right) and
Sally Atkinson (back left) of the BDA Benevolent Fund. 